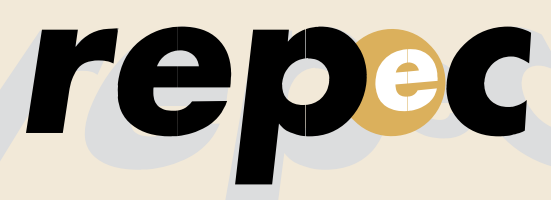

REPeC, Brasília, v. 10, n. 3, art. 5, p. 314-331, jul./set. 2016

Disponivel online em www.repec.org.br

DOl: http://dx.doi.org/10.17524/repec.v10i3.1393
Revista de Educação e Pesquisa em Contabilidade

Journal of Education and Research in Accounting

Periódico Trimestral, digital e gratuito publicado pela Academia Brasileira de Ciências Contábeis

ISSN 1981-8610

\title{
Influências da Socialização Acadêmica no Desenvolvimento das Publicações Científicas em Contabilidade no Brasil: Uma Análise dos Programas de Pós-Graduação Stricto Sensu
}

\begin{abstract}
Resumo
A presente investigação dedicou-se a responder à seguinte questão de pesquisa: Quais as influências da socialização acadêmica, promovida pelos cursos de pós-graduação stricto sensu da área contábil no Brasil, no desenvolvimento da produção científica do campo? Para tanto, foram realizadas entrevistas com 9 agentes do campo científico contábil, sendo 8 doutores e 1 pós-doutor em Contabilidade, de diversas regiões do Brasil e vinculados a diferentes PPGs, no período de 2014 a 2015. Para tratamento dos dados, foi utilizada a análise de conteúdo das entrevistas. Diante dessa problemática, os entrevistados defenderam que a maior parte dos PPGs utiliza como critério de avaliação nas disciplinas a publicação de um manuscrito ou artigo, no qual exista a participação do docente, ao menos na coautoria, visto que esse é um dos critérios avaliativos para que os PPGs continuem credenciados e recomendados pela Capes. Também foi evidenciado que o aluno é preparado para atender à qualidade formal nas publicações, deixando, em segundo plano, a qualidade política de criticar, debater e se opor, por meio da argumentação científica, às temáticas já consagradas como verdades quase inquestionáveis no campo contábil.
\end{abstract}

Palavras Chave: Contabilidade - Ensino e Pesquisa. Produção Científica. Socialização Acadêmica.

\section{Flaviano Costa}

Doutor em Controladoria e Contabilidade pela FEA/USP e Professor do Departamento de Contabilidade na Universidade Federal do Paraná (UFPR). Contato: Av. Prefeito Lothário Meissner, 632, Campus III, Jardim Botânico, Curitiba-PR, CEP.: 80210-070.

E-mail: flaviano_costa@hotmail.com

Gilberto de Andrade Martins Doutor em Administração pela FEA/USP e Professor Titular do Departamento de Contabilidade na FEA/USP. Contato: Av. Prof. Luciano Gualberto, 908, Prédio FEA III, Butantã, São Paulo-SP, CEP:: 05508-900.

E-mail: martins@usp.br 


\section{Introdução}

Muitos estudos e escritos nacionais e internacionais, em diferentes áreas, têm se dedicado à investigação do perfil epistemológico e da qualidade das publicações científicas em seus campos de atuação (Samuelson, 1994; Camí, 1997; Chow \& Harrison, 1998; Theóphilo, 2000; Chow \& Harrison, 2002; Lowe, 2003; Broome, 2004; Theóphilo, 2004; Harzing, 2005; McKneally, 2006; Martins, 2007; Castiel \& Sanz-Valero, 2007; Baggs, 2008; Moizer, 2009; Andrade, 2011; Alcadipani, 2011; Zago, 2011; Thomaz \& Muramoto, 2012; Yamamoto, Tourinho, Bastos \& Menandro, 2012; Wreszinski, 2012, Righetti, 2013; Reinach, 2013; Schekman, 2013; Wood Jr., 2014; Domingues, 2014; Bianchi, 2014; Costa, 2016; Wood Jr., 2016, entre outros). A maior parte desses estudos foca o aumento da quantidade de manuscritos e artigos, contudo, em contrapartida, também trata dos problemas qualitativos encontrados em muitas dessas pesquisas; outros tratam das condutas éticas nos processos investigativos, como as questões de microplágios, autoplágios e gerenciamento de protocolos e resultados (distorções causadas no estudo para se chegar a uma resposta desejada).

Nesse contexto, Castiel e Sanz-Valero (2007) e Wreszinsky (2012) asseveram que, no cenário contemporâneo, o processo de produção científica pode trazer alguns problemas para os campos de conhecimento, tais como: [1] o citacionismo ou estratégia de citações elogiosas, que vem a ser uma corrupção na ideia de fator de impacto; [2] ausência de desvios de teorias estabelecidas, ou seja, as pesquisas quase sempre tratam do mesmo assunto, sem muitas modificações que possam levar à evolução do campo; [3] publicações muito pulverizadas, nas quais uma pesquisa é separada em vários estudos menores para que possa ser divulgada em inúmeros meios de comunicação científica (salami science); [4] aumento do número de autores por artigo (escambo autoral), para todos saírem pontuados; e [5] problemas éticos como plágio, autoplágio e gerenciamento de protocolos.

Todavia, é necessário destacar que esse processo produtivo científico é fortemente influenciado por uma socialização acadêmica pela qual passam os pesquisadores da área ao cursarem os programas de mestrado e doutorado. Além das estruturas objetivas presentes no campo, que determinam as regras do jogo científico, existem também o habitus dos agentes, que pode ser moldado por meio das socializações pelas quais passam os pesquisadores da área, ao longo de suas trajetórias acadêmicas. Contudo, o jogo do habitus só se inicia com as cartas dadas pelo campo, e as ações dos agentes são o resultado da interação entre o habitus e o campo (Souza, 2007). Nesse sentido, é relevante o entendimento de que os programas de pós-graduação (PPGs) stricto sensu possuem papel seminal na estruturação do campo científico, porquanto devem fornecer aos investigadores subsídios para a produção e disseminação de conhecimentos que contribuam para o crescimento do campo como um todo. Todavia, cada agente vai internalizar esses conteúdos conforme a sua visão ontológica da realidade, possibilitando assim que ocorram diferentes comportamentos acadêmicos.

Refletindo acerca dos programas de pós-graduação stricto sensu, em geral, Bertero, Caldas e Wood Jr. (1999, p. 153) aduzem que o discurso oficial brasileiro defende que, em um curto espaço de tempo, os PPGs cresceram razoavelmente para um país emergente. Contudo, o problema que os autores colocam é o da qualidade, ou seja, "[...] se os programas se consolidaram com grande rapidez, resta a constatação de que continuam programas de segunda classe, no que diz respeito à qualidade da produção científica $\mathrm{e}$ ao nível de capacitação do pessoal formado". Apesar de esse estudo datar de há quase 15 anos, é nítida a sua atemporalidade diante das exposições reunidas até o presente momento e dos questionamentos pelos quais passa a produção científica como um todo.

Desse modo, é importante que se estude a forma de socialização acadêmica desempenhada pelos programas de pós-graduação stricto sensu da área contábil no Brasil, porquanto, nos últimos anos, esses PPGs cresceram em número e, conseguintemente, também aumentou, nesse período, o número de periódicos, congressos e publicações científicas em Contabilidade. Portanto, esse olhar para os PPGs é importante, visto que o objetivo de existirem é para subsidiar todo o processo de socialização acadêmica, transformando os agentes ingressantes na área em pesquisadores e docentes que trabalhem na manutenção e aperfeiçoamento do campo científico-contábil. 
Diante de todas essas exposições reunidas, a presente investigação dedica-se a responder à seguinte questão de pesquisa: Quais as influências da socialização acadêmica, promovida pelos cursos de pós-graduação stricto sensu da área contábil no Brasil, no desenvolvimento da produção científica do campo? Assim sendo, o objetivo subjacente deste estudo é analisar de que forma a socialização acadêmica influencia o processo de produção de conhecimento científico da área de Contabilidade no Brasil. Para tanto, o artigo está dividido em mais quatro seções, destinados a: [1] referencial teórico para embasar os achados da pesquisa; [2] procedimentos metodológicos utilizados; [3] apresentação e análise dos resultados e; [4] considerações finais e implicações do estudo.

\section{Socialização Acadêmica: A Construção Social da Realidade Científica}

Uma das temáticas e preocupações muito debatidas no mundo científico-tecnológico é a formação dos cientistas, que passam por todas as instâncias educacionais, desde a formação básica até os níveis mais elevados de titulação acadêmica. Assim sendo, a formação de cientistas envolve, necessariamente, visões de mundo e concepções de ciência que, por sua vez, não devem desprezar o contexto histórico no qual estão inseridas, bem como elementos políticos. Nesse contexto, Trigueiro (2001) pondera que a solução para incrementar a formação dos cientistas não é simples e demanda um esforço considerável dos programas de pós-graduação no sentido de:

[...] criar mecanismos que favoreçam, nos currículos e nas práticas acadêmicas, um ethos muito mais voltado para o intercâmbio, para a troca de experiências, até mesmo envolvendo públicos de fora das instituições de pesquisa ou de universidades, estimulando a 'escuta' junto à sociedade, através de seminários e discussões temáticas [...]. Um outro aspecto que me parece crucial na formação dos cientistas é o estímulo à criatividade. Esta, um valor importante no meio acadêmico, nem sempre vem recebendo a devida atenção, seja por parte dos programas de pós-graduação, seja pela administração superior das universidades ou dos institutos de pesquisa [...]. A academia, com todos os seus rituais, tradições e práticas de sucessão, tende a impedir ou restringir a criatividade e embotar o pensamento crítico, ainda que seja exatamente em seu nome que ela se constitua (p. 66-68).

Trigueiro (2001, p. 65-66) finaliza sua exposição, assinalando que "a principal necessidade para a formação dos cientistas contemporâneos é a ampliação considerável da comunicabilidade, em suas diferentes formas, níveis e processos, para o cotidiano desses profissionais". Nesse sentido, para se alcançar em tais atributos, é necessário que os cientistas passem por uma socialização secundária, denominada socialização acadêmica.

\subsection{Processos de Socialização}

O real entendimento da vida cotidiana é um processo complexo. Ainda que a linguagem possibilite a transmissão de conhecimentos e a comunicação entre agentes, é preciso considerar que tudo o que é transmitido ou reproduzido passa pelo crivo do receptor. Nesse sentido, visualizam-se os efeitos da subjetividade inerente ao processo interpretativo de qualquer ser humano, uma vez que o mundo em sua volta pode ser diferentemente percebido pelos demais que estão ao seu redor. Esse processo social de apreensão da realidade subjetiva está intimamente ligado com a sociologia do conhecimento, porquanto "[...] a sociologia do conhecimento diz respeito à análise da construção social da realidade" (Berger \& Luckmann, 2008, p. 14). 
Com relação à interiorização da realidade, Berger e Luckmann (2008) destacam a importância da percepção individual do processo de integração à sociedade. Ainda que todos os seres humanos integrem aquela sociedade objetivamente acessível, caracterizada pela repetição de hábitos, entre outras rotinas, tais indivíduos não nasceram diretamente como integrantes desse mundo social, mas, sim, tornaram-se parte dele. Assim posto, o processo de assunção do mundo existente como o mundo do qual se faz parte configura-se como um processo interpretativo daquilo com o qual o indivíduo se depara. Esse processo de interiorização da realidade percebida é transmitido por meio de uma socialização.

Nesse contexto, a socialização é definida como um "[...] processo ontogenético pelo qual se realiza a interiorização, que é ampla e consistente introdução de um indivíduo no mundo objetivo de uma sociedade ou setor dela [...]" (Berger \& Luckmann, 2008, p. 175). O processo de socialização distingue dois momentos - um denominado de socialização primária e outro de socialização secundária. A construção do primeiro mundo para cada um dos indivíduos dá-se na socialização primária - é um processo influenciado por questões emocionais. Caracterizada, entre outros aspectos, pelo formalismo e pelo anonimato, a socialização secundária diz respeito a um processo de interiorização de questões mais objetivas ou baseadas em instituições do mundo social. Assim, tanto na socialização primária, quanto na secundária, há interiorização de questões de ordem social, todavia, a socialização primária demanda identificação, cuja condição é dispensável à socialização secundária.

Uma vez que o caráter de identidade não é condição à socialização secundária, seus preceitos não se encontram profundamente enraizados na consciência dos indivíduos, tornando tal socialização mais vulnerável às alterações. Por outro lado, a transformação de aspectos construídos durante o processo de socialização primária é mais complexa, todavia, não extingue a possibilidade de sua modificação. Salienta-se que tais modificações exigem processos denominados de ressocialização (procedimento semelhante à socialização primária, no entanto, requerente de todo um arcabouço social para fomentar tal transformação). Assim, o passado configura-se como propulsor da socialização secundária, ao passo que o presente representa a realidade de base da ressocialização. Nessa mesma linha argumentativa, Duarte Jr. (2008, p. 81) defende que "[...] como o conhecimento assimilado na socialização secundária é menos marcado afetivamente, ele pode mais facilmente ser colocado entre parênteses, isto é, esquecido ou deixado de lado".

Portanto, a socialização secundária "[...] é qualquer processo subsequente que introduz um indivíduo já socializado em novos setores do mundo objetivo de sua sociedade”, ou seja, é a interiorização de submundos institucionais ou baseados em instituições (Berger \& Luckmann, 2008, p. 175). Nesse contexto, pode-se depreender que a socialização acadêmica é uma espécie de socialização secundária, que insere o agente no mundo científico, fornecendo-lhe o status de cientista, por meio de ensinamentos e orientações sobre as regras do jogo científico definidas pelas instituições e agentes presentes no campo.

\subsection{Programas de Pós-Graduação no Brasil}

Até o mês de junho de 2016, estão funcionando no Brasil vinte e oito programas de pós-graduação stricto sensu na área contábil, alguns com cursos de mestrado e doutorado acadêmicos, outros somente com mestrado profissional ou acadêmico. A maior parte desses PPGs surgiu há pouco tempo e aumentou o volume de publicações científicas na área contábil, devido às dissertações e teses desenvolvidas e defendidas nesses programas. Todavia, pode-se depreender que a qualidade não acompanha o volume dessas comunicações científicas, que tendem a priorizar os aspectos de produtividade quantitativa. No Quadro 1, estão elencados os PPGs strictu sensu da área contábil no Brasil, reconhecidos pela Capes (recorte até junho de 2016). 


\begin{tabular}{|c|c|c|c|c|}
\hline Programa & Instituição de Ensino Superior & MP & MA & D \\
\hline Administração e Controladoria & Universidade Federal do Ceará & & $X$ & \\
\hline Ciências Contábeis & Universidade de Brasília & & $x$ & $x$ \\
\hline Ciências Contábeis & Universidade Federal do Espírito Santo & & $X$ & \\
\hline Ciências Contábeis & $\begin{array}{l}\text { Fundação Instituto Capixaba de Pesquisas em } \\
\text { Contabilidade, Economia e Finanças }\end{array}$ & $x$ & $x$ & $x$ \\
\hline Ciências Contábeis & Universidade Federal de Goiás & & $x$ & \\
\hline Ciências Contábeis & Universidade Federal de Minas Gerais & & $X$ & \\
\hline Ciências Contábeis & Universidade Federal de Uberlândia & & $x$ & $x$ \\
\hline Ciências Contábeis & Universidade Federal da Paraíba & & $X$ & $X$ \\
\hline Ciências Contábeis & Universidade Federal de Pernambuco & & $X$ & $x$ \\
\hline Ciências Contábeis & Universidade Estadual de Maringá & & $x$ & \\
\hline Ciências Contábeis & Universidade Federal do Rio de Janeiro & & $X$ & $X$ \\
\hline Ciências Contábeis & Universidade do Vale do Rio dos Sinos & & $x$ & $x$ \\
\hline Ciências Contábeis & Universidade Federal do Rio Grande do Norte & & $X$ & \\
\hline Ciências Contábeis & Universidade Regional de Blumenau & & $x$ & $x$ \\
\hline Ciências Contábeis & Universidade Presbiteriana Mackenzie & $X$ & & \\
\hline Ciências Contábeis & Centro Universitário Fecap & & $X$ & \\
\hline Ciências Contábeis e Administração & Universidade Comunitária da Região Chapecó & & $x$ & \\
\hline Ciências Contábeis e Atuariais & Pontifícia Universidade Católica de São Paulo & & $X$ & \\
\hline Contabilidade & Universidade Federal da Bahia & & $X$ & \\
\hline Contabilidade & Universidade Federal do Paraná & & $x$ & $x$ \\
\hline Contabilidade & Universidade Estadual do Oeste do Paraná & & $x$ & \\
\hline Contabilidade & Universidade Federal de Santa Catarina & & $x$ & $x$ \\
\hline Contabilidade UNB - UFPB - UFRN & Universidade de Brasília & & $X$ & $x$ \\
\hline Controladoria & Universidade Federal Rural de Pernambuco & & $x$ & \\
\hline Controladoria e Contabilidade & Universidade Federal do Rio Grande do Sul & & $x$ & \\
\hline Controladoria e Contabilidade & Universidade de São Paulo & & $X$ & $x$ \\
\hline Controladoria e Contabilidade & Universidade de São Paulo - Ribeirão Preto & & $x$ & $X$ \\
\hline
\end{tabular}

Quadro 1. Programa de Pós-graduação strictu sensu em Contabilidade no Brasil

Fonte: Capes (2016)

Em todas as missões dos mestrados e doutorados acadêmicos, aparecem a preocupação com a formação científica e docente dos egressos, por meio de uma socialização secundária, que transmita ao aluno o status quo do pensamento científico-contábil e as regras do jogo científico impostas pelas instituições que estruturam o campo. Tal preocupação está alinhada com a Lei da Reforma Universitária n. ${ }^{\circ}$ 5.540/1968, que estabeleceu como objetivos dos PPGs: [1] formar professores para o ensino superior; [2] preparar pessoal de alta qualificação para as empresas públicas e privadas; e [3] estimular estudos e pesquisas científicas por meio da formação de pesquisadores, que servissem ao desenvolvimento do País.

Nesse contexto, pode-se observar que a Contabilidade, enquanto objeto científico, ainda é incipiente, visto que a maioria dos PPGs strictu sensu da área contábil surgiram há menos de dez anos atrás. A implantação do primeiro PPG strictu sensu em Contabilidade no Brasil foi em 1970, na Faculdade de Administração, Economia e Contabilidade da Universidade de São Paulo (FEA/USP). Ainda na década de 1970, foi criado o Programa de Mestrado em Ciências Contábeis da Fundação Getúlio Vargas, que, por motivos de reestruturação, em 1991, passou para a Universidade Estadual do Rio de Janeiro. Em 1978, foi implantado o Programa de Doutorado da FEA/USP, que até poucos anos atrás era o único em vigor em todo o Brasil (Peleias, Silva, Segreti \& Chirotto, 2007). 
Complementarmente, os autores mencionam que, ao longo da década de 1980, não surgiram novos PPGs, o que voltou a ocorrer a partir da década de 1990, devido aos seguintes pontos: [1] exigências da Lei n. ${ }^{\circ}$ 9394/1996 de que, ao menos, um terço dos profissionais docentes de ensino superior, nos centros universitários e universidades, tenham titulação mínima de mestrado e existam professores em regime de tempo integral dedicados ao ensino e pesquisa; [2] aumento dos cursos de ensino superior em contabilidade no Brasil; e [3] aumento do número de professores doutores em Contabilidade no Brasil. Com esse crescimento dos PPGs houve um incremento numérico das pesquisas e o surgimento de novos congressos, encontros e periódicos na área contábil. Nessa perspectiva de análise, também surge para orientar e estabelecer diretrizes para os programas de pós-graduação a Coordenação de Aperfeiçoamento de Pessoal de Nível Superior [Capes], estabelecendo padrões de medição de qualidade para esses programas.

\subsection{Capes: As Regras do Jogo Científico Brasileiro}

A Capes é quem realiza trienalmente a avaliação dos programas de pós-graduação, desde sua implantação ocorrida em 1976. Nesse sentido, cumpre um papel de relevância no cenário do desenvolvimento científico e tecnológico brasileiro, tendo como principais atribuições: [1] impulsionar a evolução dos PPGs, antepondo-lhe metas e desafios que sinalizem os avanços da ciência e tecnologia na atualidade e o aumento da competência nacional nesse campo; [2] aprimorar os PPGs, assegurando-lhes um parecer criterioso sobre os pontos fortes e fracos de seu projeto e de seu desempenho e uma referência sobre o estágio de desenvolvimento em que se encontra; [3] dotar o país de um eficiente banco de dados sobre a situação e evolução da pós-graduação; [4] estabelecer o padrão de qualidade exigido desse nível de ensino e identificar os programas que atendem a tal padrão; [5] fundamentar, nos termos da legislação em vigor, os pareceres do Conselho Nacional de Educação sobre autorização, reconhecimento e renovação de reconhecimento dos cursos de mestrado e doutorado brasileiros; [6] contribuir para o aumento da eficiência dos programas no atendimento das necessidades nacionais e regionais de formação de recursos humanos de alto nível; e [7] oferecer subsídios para a definição da política de desenvolvimento da pós-graduação e para a fundamentação de decisões sobre as ações de fomento dos órgãos governamentais na pesquisa e pós-graduação (Cunha, 2007; Capes, 2015).

No Brasil, os PPGs são avaliados de acordo com a Portaria n. ${ }^{\circ}$ 68/2004 da Capes. Um ponto comum entre a avaliação dos programas de pós-graduação e dos professores que podem fazer parte desses PPGs é a produção científica produzida por eles. Nesse contexto, a Capes realiza avaliações trienais dos periódicos das áreas de conhecimento por meio do Qualis, que pode ser compreendido como um conjunto de ferramentas utilizadas para mensurar a qualidade da produção intelectual dos PPGs. Esse sistema Qualis atribui um estrato a cada periódico, de acordo com a sua qualidade, mensurado pelo somatório de pontos obtidos por cada artigo nele publicado, iniciando em A1 (estrato mais elevado), A2, B1, B2, B3, B4, B5 e C, com peso zero (CAPES, 2016). De acordo com Martins e Lucena (2014), esse sistema avaliativo proporcionou tanto um avanço à pós-graduação brasileira, quanto consequências de pesquisas superficiais e pouco relevantes devido às pressões por publicações para obtenção de pontuação necessária para uma boa avaliação.

Assim, unindo as duas extremidades: socialização acadêmica e avaliação dos cursos de mestrado e doutorado, percebe-se que a problemática é ainda maior, porquanto, os PPGs pressionados para manter uma nota mínima e continuar funcionando, acabam repassando essa visão produtivista a seus alunos, fazendo-os produzir em massa, sem, muitas vezes, o devido tempo de maturação sobre o que está sendo pesquisado. Essa é a razão de se verificar textos superficiais, pesquisas replicadas, muitas vezes, e problemas éticos de plágios e autoplágios nos textos científicos. Desse modo, chega-se à problemática dessa pesquisa de levantar esse cenário de desenvolvimento científico, relacionando às evidências obtidas nas análises realizadas sobre a socialização acadêmica para melhor compreender os contornos dados à pesquisa científica contábil na atualidade. 


\section{Procedimentos Metodológicos}

Os procedimentos metodológicos são fundamentais para as pesquisas de caráter científico, visto que, segundo Demo (1995), a atividade da pesquisa é a razão fundante da vida acadêmica e necessita de métodos para ser operacionalizada. Nesses termos, essa seção tem por finalidade descrever o constructo principal da investigação, a amostra utilizada na pesquisa, a técnica de coleta de dados e evidências e o tratamento dado às informações coletadas no estudo.

\subsection{Constructo e Definição Operacional da Pesquisa}

O constructo principal da investigação é a socialização acadêmica, que, para a presente pesquisa, representa o processo pelo qual passam todos os agentes imbricados no campo científico. É uma espécie de socialização secundária, que tem por objetivo primordial incentivar a produção do conhecimento por meio das técnicas de ensino e pesquisa e formar docentes que atendam às exigências de qualificação dos cursos superiores (Bourdieu, 2004; Berger \& Luckmann, 2008), no caso em questão, para a área contábil.

Neste estudo, a socialização acadêmica é utilizada como premissa fundamental para o entendimento do campo científico contábil, porque se supõe que ela é o primeiro elemento que influencia e legitima o processo de construção do saber e, nesse sentido, influencia diretamente a forma como os agentes habitualmente atuam no campo. Portanto, a operacionalização do constructo "socialização acadêmica" ocorre por meio de entrevistas, com o intuito de levantar a percepção dos agentes sobre a maneira com que os PPGs em Contabilidade transmitem a seus alunos as regras do jogo científico e as características das estruturas sociais presentes no campo.

\subsection{População e Amostra}

A população da pesquisa é constituída pelos pesquisadores da área contábil que passaram por uma socialização acadêmica em nível de mestrado e doutorado ou pós-doutorado na área contábil, para compreensão do constructo relativo à socialização acadêmica. Contudo, torna-se inviável o estudo da população toda. Por esse motivo e pelo fato de a pesquisa privilegiar os dados em profundidade e, não, em amplitude, optou-se em entrevistar 9 pesquisadores da área em profundidade, sendo 8 doutores em 1 pós-doutor em Contabilidade, de diferentes regiões do País e vinculados a diferentes Instituições de Ensino Superior (IES). A amostragem foi intencional, visto que o critério de escolha dos agentes foi a disponibilidade destes para responder à entrevista. O Quadro 2 detalha melhor o perfil dos respondentes, mantendo o anonimato de cada um deles. 


\begin{tabular}{|c|c|}
\hline Respondente & Descrição detalhada das atividades desenvolvidas academicamente \\
\hline Entrevistado 1 & $\begin{array}{l}\text { Formação: Doutor em Controladoria e Contabilidade. } \\
\text { Ano de obtenção do título: } 2007 . \\
\text { Região em que atua: Sudeste. } \\
\text { Atividades desenvolvidas: [1] participa ou participou como membro da American Accounting Association; } \\
\text { [2] participa ou participou como membro-diretor da Associação Nacional de Programas de Pós-Graduação } \\
\text { em Ciências Contábeis (ANPCONT); [3] participa ou participou como membro do Comitê Científico da } \\
\text { Associação Nacional de Pós-Graduação e Pesquisa em Administração (Anpad); [4] é membro de comitês } \\
\text { editoriais e revisor de periódicos nacionais e internacionais; [5] possui extensa produção bibliográfica na } \\
\text { área de Contabilidade e Finanças (mais de } 50 \text { artigos publicados em congressos e periódicos nacionais e } \\
\text { internacionais). } \\
\text { Objetos de Pesquisa: Contabilidade e Finanças; Mercado de Capitais; Governança Corporativa; Mercado } \\
\text { Financeiro e Disclosure. } \\
\text { Capacidade formativa: [1] professor de curso de graduação, mestrado e doutorado em Contabilidade; [2] } \\
\text { orienta e orientou inúmeros trabalhos de conclusão de curso em graduação, } 6 \text { dissertações de mestrado e } \\
8 \text { teses de doutorado, além de ter desenvolvido projetos de iniciação científica. }\end{array}$ \\
\hline Entrevistado 2 & $\begin{array}{l}\text { Formação: Doutor em Controladoria e Contabilidade. } \\
\text { Ano de obtenção do título: } 2009 . \\
\text { Região em que atua: Sudeste. } \\
\text { Atividades desenvolvidas: [1] é membro de comitês editoriais e revisor de periódicos nacionais; [2] possui } \\
\text { extensa produção bibliográfica na área de Contabilidade e Finanças (mais de } 60 \text { artigos publicados em } \\
\text { congressos e periódicos nacionais e internacionais). } \\
\text { Objetos de Pesquisa: Contabilidade e Finanças; Mercado de Capitais; Direito Privado. } \\
\text { Capacidade formativa: [1] professor de curso de graduação, mestrado e doutorado em Contabilidade; [2] } \\
\text { orienta e orientou inúmeros trabalhos de conclusão de curso em graduação, } 2 \text { dissertações de mestrado e } \\
4 \text { teses de doutorado. }\end{array}$ \\
\hline Entrevistado 3 & $\begin{array}{l}\text { Formação: Pós-doutor em Controladoria e Contabilidade. } \\
\text { Ano de obtenção do título: } 2013 . \\
\text { Região em que atua: Sul. } \\
\text { Atividades desenvolvidas: [1] atua ou atuou como avaliador institucional do Instituto Nacional de Estudos } \\
\text { e Pesquisas Educacionais Anísio Teixeira (Inep); [2] participa ou participou como membro da Comissão } \\
\text { Coordenadora do Exame Nacional de Desempenho dos Estudantes (Enade) na área de Ciências Contábeis; } \\
\text { [3] é membro de comitês editoriais e revisor de periódicos nacionais; [4] participa ou participou como } \\
\text { membro do Comitê Científico da Anpad e do Congresso USP de Controladoria e Contabilidade; [5] possui } \\
\text { extensa produção bibliográfica na área de Contabilidade (mais de } 150 \text { artigos publicados em congressos e } \\
\text { periódicos nacionais e internacionais); [6] atua ou atuou como consultor ad hoc em processos de análise e } \\
\text { julgamento de mérito e validade técnico-científicas de projetos de pesquisa para o Conselho Nacional de } \\
\text { Desenvolvimento Científico e Tecnológico (CNPq). } \\
\text { Objetos de Pesquisa: Contabilidade e Finanças; Ensino de Contabilidade e Finanças. } \\
\text { Capacidade formativa: [1] professor de curso de graduação, mestrado e doutorado em Contabilidade; } \\
\text { [2] bolsista de Produtividade em Pesquisa do CNPq - Nível 2; [3] orienta e orientou inúmeros trabalhos de } \\
\text { conclusão de curso em graduação, } 16 \text { dissertações de mestrado e } 2 \text { teses de doutorado. }\end{array}$ \\
\hline Entrevistado 4 & $\begin{array}{l}\text { Formação: Doutor em Controladoria e Contabilidade. } \\
\text { Ano de obtenção do título: } 1996 . \\
\text { Região em que atua: Sudeste. } \\
\text { Atividades desenvolvidas: [1] participa ou participou como membro diretor da ANPCONT; [2] é membro } \\
\text { de comitês editoriais e revisor de periódicos nacionais e internacionais; [3] atua ou atuou como membro } \\
\text { de comissões de avaliação da Capes da área de Administração, Contabilidade e Turismo; [4] é membro do } \\
\text { Comitê Assessor do CNPq das área de Administração e Contabilidade; [5] atua ou atuou como editor-chefe } \\
\text { da Revista Contabilidade \& Finanças da Universidade de São Paulo; [6] é um dos coeditores convidados } \\
\text { pela Esmerald para desenvolvimento de ediçães especiais em periódicos internacionais; [7] participa } \\
\text { ou participou como membro do European Accounting Association (EAA); [8] possui extensa produção } \\
\text { bibliográfica na área de Contabilidade (mais de } 150 \text { artigos publicados em congressos e periódicos } \\
\text { nacionais e internacionais). } \\
\text { Objetos de Pesquisa: Controle Gerencial, Contabilidade Gerencial e Controladoria. } \\
\text { Capacidade formativa: [1] professor de curso de graduação, mestrado e doutorado em Contabilidade; [2] } \\
\text { bolsista de Produtividade em Pesquisa do CNPq - Nível 1A; [3] orienta e orientou inúmeros trabalhos de } \\
\text { conclusão de curso em graduação, } 22 \text { dissertações de mestrado e } 17 \text { teses de doutorado. }\end{array}$ \\
\hline
\end{tabular}




\begin{tabular}{|c|c|}
\hline Respondente & Descrição detalhada das atividades desenvolvidas academicamente \\
\hline Entrevistado 5 & $\begin{array}{l}\text { Formação: Doutor em Controladoria e Contabilidade. } \\
\text { Ano de obtenção do título: } 2002 . \\
\text { Região em que atua: Sul. } \\
\text { Atividades desenvolvidas: [1] é membro de comitês editoriais e revisor de periódicos nacionais; [2] atua ou } \\
\text { atuou como editor-chefe de revistas científicas no Brasil; [3] possui extensa produção bibliográfica na área } \\
\text { de contabilidade (mais de } 150 \text { artigos publicados em congressos e periódicos nacionais e internacionais). } \\
\text { Objetos de Pesquisa: Controle Gerencial, Contabilidade Gerencial e Controladoria. } \\
\text { Capacidade formativa: [1] professor de curso de graduação, mestrado e doutorado em Contabilidade; [2] } \\
\text { orienta e orientou inúmeros trabalhos de conclusão de curso em graduação, } 20 \text { dissertações de mestrado } \\
\text { e } 4 \text { teses de doutorado. }\end{array}$ \\
\hline Entrevistada 6 & $\begin{array}{l}\text { Formação: Doutora em Controladoria e Contabilidade. } \\
\text { Ano de obtenção do título: } 2007 . \\
\text { Região em que atua: Sudeste. } \\
\text { Atividades desenvolvidas: [1] é membro de comitês editoriais e revisor de periódicos nacionais; [2] atua ou } \\
\text { atuou como editora-chefe da de revistas científicas no Brasil; [3] é membro do Comitê Assessor do CNPq da } \\
\text { área de Administração e Contabilidade; [4] possui extensa produção bibliográfica na área de Contabilidade } \\
\text { (mais de } 120 \text { artigos publicados em congressos e periódicos nacionais e internacionais). } \\
\text { Objetos de Pesquisa: Ensino e Pesquisa em Contabilidade; Sustentabilidade e Contabilidade Ambiental. } \\
\text { Capacidade formativa: [1] professora de curso de graduação e mestrado em Contabilidade; [2] bolsista de } \\
\text { Produtividade em Pesquisa do CNPq - Nível 2; [3] orienta e orientou inúmeros trabalhos de conclusão de } \\
\text { curso em graduação e } 12 \text { dissertações de mestrado. }\end{array}$ \\
\hline Entrevistado 7 & $\begin{array}{l}\text { Formação: Doutor em Controladoria e Contabilidade. } \\
\text { Ano de obtenção do título: } 2009 . \\
\text { Região em que atua: Sudeste. } \\
\text { Atividades desenvolvidas: [1] é membro de comitês editoriais e revisor de periódicos nacionais e } \\
\text { internacionais; [2] atua ou atuou como professor visitante em universidades internacionais; [3] atua } \\
\text { ou atuou como um dos representantes no projeto de internacionalização do PPG em Controladoria } \\
\text { e Contabilidade da FEA/USP (STAR Comission); [4] possui extensa produção bibliográfica na área de } \\
\text { contabilidade (mais de } 110 \text { artigos publicados em congressos e periódicos nacionais e internacionais). } \\
\text { Objetos de Pesquisa: Controle Gerencial, Contabilidade Gerencial e Controladoria. } \\
\text { Capacidade formativa: [1] professor de curso de graduação, mestrado e doutorado em Contabilidade; [3] } \\
\text { orienta e orientou inúmeros trabalhos de conclusão de curso em graduação, } 2 \text { dissertações de mestrado e } \\
3 \text { teses de doutorado. }\end{array}$ \\
\hline Entrevistada 8 & $\begin{array}{l}\text { Formação: Doutora em Controladoria e Contabilidade. } \\
\text { Ano de obtenção do título: } 2008 . \\
\text { Região em que atua: Centro-Oeste. } \\
\text { Atividades desenvolvidas: [1] é membro de comitês editoriais e revisora de periódicos nacionais; [2] atua } \\
\text { ou atuou como avaliadora institucional do Inep; [3] atua ou atuou como consultora ad hoc na avaliação } \\
\text { de projetos de pesquisa para a Fundação Araucária de Apoio e Desenvolvimento Científico e Tecnológico; } \\
\text { [4] possui extensa produção bibliográfica na área de Contabilidade (mais de } 180 \text { artigos publicados em } \\
\text { congressos e periódicos nacionais e internacionais). } \\
\text { Objetos de Pesquisa: Ensino e Pesquisa em Contabilidade, Controle Gerencial, Controladoria e } \\
\text { Contabilidade Gerencial. } \\
\text { Capacidade formativa: [1] atuou ou atua como professora de curso de graduação e mestrado e doutorado } \\
\text { em Contabilidade; [2] bolsista de Produtividade em Pesquisa do CNPq - Nível 2; [3] orienta e orientou } \\
\text { inúmeros trabalhos de conclusão de curso em graduação e } 22 \text { dissertações de mestrado. }\end{array}$ \\
\hline Entrevistada 9 & $\begin{array}{l}\text { Formação: Doutora em Controladoria e Contabilidade. } \\
\text { Ano de obtenção do título: } 1997 . \\
\text { Região em que atua: Nordeste. } \\
\text { Atividades desenvolvidas: [1] é membro de comitês editoriais e revisora de periódicos nacionais e } \\
\text { internacionais; [2] atua ou atuou como coordenadora de comissões de avaliação da Capes da área } \\
\text { de Administração, Contabilidade e Turismo; [3] atua ou atuou como avaliadora institucional do Inep; } \\
\text { [4] participa ou participou como membro da Comissão Coordenadora do Enade na área de Ciências } \\
\text { Contábeis; [5] possui extensa produção bibliográfica na área de Contabilidade (mais de } 200 \text { artigos } \\
\text { publicados em congressos e periódicos nacionais e internacionais). } \\
\text { Objetos de Pesquisa: Ensino e Pesquisa em Contabilidade, Demonstração do Valor Adicionado e } \\
\text { Contabilidade Socioambiental. } \\
\text { Capacidade formativa: [1] atuou ou atua como professora de curso de graduação e mestrado e doutorado } \\
\text { em Contabilidade; [2] bolsista de Produtividade em Pesquisa do CNPq - Nível 2; [3] orienta e orientou } \\
\text { inúmeros trabalhos de conclusão de curso em graduação, } 36 \text { dissertações de mestrado e } 1 \text { tese de } \\
\text { doutorado. }\end{array}$ \\
\hline
\end{tabular}

Quadro 2. Formação e Vínculo Institucional dos Respondentes da Pesquisa 
Nesses termos, percebe-se que a base de respondentes foi heterogênea em termos de vinculações institucionais, atividades acadêmicas desenvolvidas, objetos de pesquisa, capacidade formativa e também geograficamente. É importante salientar que a amostra tem poucos entrevistados porque se privilegiou a análise aprofundada, e não foi intenção a generalização dos resultados da pesquisa, o que em nada invalida as evidências obtidas na presente investigação.

\subsection{Coleta de Dados, Informações e Evidências}

Para a coleta dos dados referentes à socialização acadêmica dos agentes pertencentes ao campo científico-contábil, foi utilizada a entrevista. De acordo com Martins e Theóphilo (2009, p. 88), o objetivo da entrevista é "[...] entender e compreender o significado que entrevistados atribuem a questões e situações, em contextos que não foram estruturados anteriormente, com base nas suposições e conjecturas do pesquisador". A entrevista foi em profundidade e semiestruturada porque foi conduzida por um roteiro, mas com liberdade de se poderem acrescentar novas questões que porventura aparecessem no decorrer das entrevistas. Com a aquiescência prévia dos respondentes, o processo todo foi gravado e, posteriormente, transcrito para se efetuarem as análises necessárias.

As entrevistas foram marcadas com antecedência e realizadas no período de novembro de 2014 a maio de 2015. Somente os 9 entrevistados da amostra se mostraram interessados em participar da pesquisa, em um total de 36 indivíduos que foram convidados a responder aos questionamentos da entrevista. O período de entrevistas foi longo devido à demora ou falta de respostas aos e-mails enviados para os convidados a participarem da pesquisa; ou pelo prazo, às vezes, um pouco dilatado, de marcação das entrevistas, por parte dos entrevistados, que, em muitas ocasiões, não dispunham de agenda livre.

Outro fator relevante a ser destacado é que toda a documentação seguiu critérios rigorosos de ética na pesquisa. Antes da entrevista, os respondentes assinaram um termo de consentimento para gravação de áudio das entrevistas. Esses cuidados foram relevantes para que a investigação pudesse apresentar transparência nos resultados e para garantir o anonimato dos agentes que, na presente pesquisa, foram designados por ordem numérica, ou seja, Entrevistado 1, Entrevistado 2, e assim sucessivamente.

Por fim, antes da aplicação da entrevista aos respondentes, também foi realizado um pré-teste com quatro entrevistados doutorandos da Faculdade de Economia, Administração e Contabilidade da Universidade de São Paulo, que apontaram possíveis inconsistências e dificuldades na forma de responder às questões. Dois desses quatro agentes avaliaram a validade de face ou validade aparente - que sinaliza se o instrumento mede aquilo que se propõe a medir - mas, como esse processo é subjetivo, simples e, algumas vezes, pouco satisfatório (Martins \& Theóphilo, 2009), os outros dois agentes também foram convidados a validar o conteúdo que cada questão procurou medir e responderam ao formulário de validação de conteúdo, para garantir que o roteiro de entrevista fosse validado.

\subsection{Tratamento e Análise dos Dados}

Para responder à questão de pesquisa proposta na investigação, foi utilizada a técnica de análise de conteúdo das entrevistas. Tal técnica busca compreender, de forma confiável, o conteúdo de discursos orais e/ou escritos, composto por dados e informações de determinado contexto, pronunciados por agentes de um dado campo ou área de atuação (Martins \& Theóphilo, 2009; Bardin, 2009). Neste artigo, a análise de conteúdo buscou entender e explicar as atitudes, valores e percepções dos agentes imbricados no campo científico da Contabilidade, mediante o exame das entrevistas realizadas com os respondentes. 


\section{Apresentação e Análise dos Resultados}

A preocupação foi verificar de que forma a socialização acadêmica influencia a maneira que os agentes enxergam as atividades de produção e publicação científica. Assim sendo, foi exposto aos 9 respondentes da amostra que os pesquisadores que passaram por um programa de mestrado ou doutorado em Contabilidade vivenciaram uma socialização acadêmica, e que muitos desses programas incentivam fortemente a publicação de papers no período de vinculação do aluno com a instituição. Diante disso, perguntou-se a eles como essa socialização influencia a qualidade e o desenvolvimento das publicações científicas contábeis.

Diante desse questionamento, o Entrevistado 2 asseverou que a socialização acadêmica pode influenciar, tanto positivamente quanto de forma negativa, a qualidade das comunicações científicas da área contábil. Nesse sentido, o respondente iniciou suas ponderações afirmando que os novos PPGs necessitam se consolidar no mercado acadêmico e, por isso, existe uma pressão muito grande para que os docentes e, por consequência, os discentes, vinculados a esses programas publiquem muitos manuscritos e artigos em congressos e periódicos, avaliados positivamente no sistema Qualis da Capes para somar uma pontuação suficiente para manter ou elevar a nota no triênio em que está sendo avaliado. Nesse cenário, o Entrevistado 2, ao levantar o ponto positivo da socialização acadêmica, lembrando de sua época de mestrado, afirmou que:

Então, o ponto positivo disso, no meu entendimento, foi: ela [socialização acadêmica] me propiciou e propiciou para as pessoas que estavam junto um treinamento em pesquisa, [...] no meu caso e no caso da maioria das pessoas que estavam ali, que estavam vindo da graduação, sem nunca ter aberto um paper na vida, sem nunca saber o que era uma pesquisa, foi um treinamento do zero. Então, no meu caso específico eu não tinha feito TCC, eu nunca tinha lido um artigo científico. Nesse caso, a gente saiu do zero e aprendeu a fazer um paper, uma dissertação ao final desse processo, digamos assim, razoável. Assim, todos esses artigos que a gente fez de maneira intermediária nas disciplinas, o aspecto positivo que teve na qualidade eu acho que foi o fato de que a gente treinou bastante.

Contudo, esse processo de socialização acadêmica, aliado com o publicacionismo promovido por alguns dos PPGs em Contabilidade também possui aspectos negativos sob o ponto de vista do respondente, porquanto, segundo ele, "[...] o ponto negativo é essa questão de sair muito lixo ao longo desse processo, das pessoas acabarem fazendo muitos artigos e, naturalmente quando se faz muito, você não faz nada bom, ainda não se tem também a maturidade para se fazer algo muito decente [...]" (Entrevistado 2). Finalizando suas percepções sobre os aspectos negativos proporcionados pela dualidade socialização acadêmica $\mathrm{x}$ qualidade das comunicações científicas contábeis, o Entrevistado 2 advertiu que:

Então acaba prejudicando a qualidade dos trabalhos, no geral, porque acaba que banalizando um pouco a questão da pesquisa, banalizando um pouco a questão de publicação, porque o pesquisador começa a publicar tanto que vira meio que uma indústria de publicação e acaba perdendo a relevância. As pessoas acabam se perdendo nesse processo e o resultado é aquilo que a gente conhece, um monte de artigo que não serve para nada, que ninguém lê [...]. Talvez um meio termo fosse passar pelo treinamento, talvez com o mesmo artigo ou com um ou dois artigos para que você fosse trabalhando na questão de um working paper e fosse evoluindo o mesmo trabalho que seria obviamente a dissertação ou partes da dissertação ou alguma coisa correlacionada, e aí você fosse evoluindo o próprio trabalho e no final você teria uma ou duas publicações ao longo desse processo, mas de qualidade. 
Nesses termos, é salutar destacar que o hábito da escrita científica é relevante para o crescimento da ciência, e que a crítica feita pelo respondente é quanto à qualidade do que está sendo escrito. Colaborando para esse entendimento, o Entrevistado 7 argumentou, que em sua percepção, os cursos de mestrado e doutorado precisam exercitar o "fazer pesquisa", mas discordou que esse treinamento necessite ir até o ponto de uma publicação, pois acredita que o tempo é muito pouco para que haja um amadurecimento necessário para que se consiga minimamente elaborar uma investigação com qualidade. Assim sendo, a Entrevistada 6 afirmou que "[...] nada que é feito sem prazer e um pouco de amadurecimento sai com uma boa qualidade e gera um stress adicional no discente".

Nessa mesma linha de raciocínio, o Entrevistado 5 ponderou que não é possível fazer publicações de qualidade no tempo de duração de uma disciplina (geralmente quatro a cinco meses), porque, para que um manuscrito ou artigo fique robusto e em condições de ser divulgado, é necessária aplicação de tempo na escolha do problema a ser respondido, na formulação de hipóteses, na seleção do método mais adequado para responder à questão proposta e na coleta, tratamento e interpretação dos dados, informações e evidências da pesquisa, bem como nas considerações conclusivas do estudo. Do mesmo modo, o Entrevistado 4, tendo por base o seu modo de agir como professor afiançou que:

[...] Só para você entender, os alunos que eu oriento, em termos de dissertação e tese, eu deixo claro para eles que eu gostaria de publicar com eles, mas se eles não quiserem é um problema deles. E se eles quiserem que o meu nome saia eu estou lá para discutir tudo, porque artigo é uma coisa e tese é outra. Tese tem uma lógica, tem um conteúdo, tem uma extensão, e a comunicação de um artigo ela é muito mais restrita, resumida, é o filé mignon e você inclusive tem chances de aprender coisas que você não aprendeu durante a montagem da tese. Essa éa grande sacada do processo e que deve ser preservada. E aí eu também me manifesto contra os programas que o aluno, quando ele entrega o trabalho, tem que entregar também artigo, junto com o professor [...], quer dizer, o cara tem que fazer artigo e além disso tem que entregar a tese e a dissertação, é muito complicado, porque vai sair um trabalho de baixa qualidade e vai gerar produtivismo.

Colaborando para esse entendimento, o Entrevistado 3 acredita que não se pode nem chamar de socialização acadêmica esse processo compulsório de vinculação da produção acadêmica de discentes e docentes por meio do produtivismo. Para o respondente, existe tão somente um jogo de interesses, no qual o discente produz, em tempo razoavelmente curto um artigo. Isso é recompensado mediante um conceito ou uma nota para que o aluno possa concluir os créditos de determinada disciplina. Todo esse procedimento traz consigo uma baixa na qualidade dessas comunicações científicas, visto que existem limitações de tempo e até mesmo de conhecimento para que se possa escrever um paper com a qualidade e profundidade necessárias para o crescimento científico da área. Diante disso, o Entrevistado 3 asseverou que:

Essa socialização ocorre quando eu estabeleço, por exemplo, redes de pesquisas ou investigações em torno de grupos. Nesse contexto, há socialização e aí a disciplina ajuda. Agora, se o professor estabelecer como métricas de aprovação a elaboração de um artigo nos padrões do congresso, por exemplo, ANPCONT, que é da nossa área, ou do Congresso da USP e deixar que o congresso corrija o artigo do sujeito para que depois ele estabeleça o conceito da disciplina, aí não há socialização. Aí há uma promoção da produção científica de uma forma que eu julgo, inclusive, incoerente.

Nesses termos, a Entrevistada 8 aduziu que, se a atividade de pesquisa for sistematizada e estruturada de forma que o pesquisador discente se vincule a laboratórios e projetos de pesquisa, isso favorecerá a qualidade, porquanto, nesse caso, existe uma troca de experiências entre pesquisadores docentes e discentes que propicia o avanço científico do campo. Todavia, para a respondente, se a preocupação for coautoria por formalidade ou para atender às regras da Capes para pontuação de programas de pós-graduação, então, as comunicações científicas são feitas apenas como moeda de troca e perde-se a relevância e a qualidade das pesquisas como um todo. 
Diante de todo esse contexto, o Entrevistado 5 defendeu também que o excesso de disciplinas é uma realidade a ser repensada nos PPGs em Contabilidade, pois são exigidas dos alunos, normalmente, que se cursem sete ou oito disciplinas para que se cumpram os créditos mínimos de programa, sendo até quatro obrigatórias. Complementarmente, o respondente levantou a importância de os programas de pós-graduação disponibilizarem conteúdos de aprendizagem que promovam o treinamento em pesquisa para os discentes, de forma obrigatória, visto que a maioria dos PPGs se preocupam apenas com a parte técnica e negligenciam disciplinas como "Metodologia da Pesquisa Científica", "Seminários de Tese", "Epistemologia da Ciência”, entre outras.

Outro fator relevante levantado pelo Entrevistado 5 é a vinculação dos cursos de mestrado e doutorado com a graduação. Para esse respondente, nas instituições que possuem os programas de pós-graduação não se percebe uma melhoria da qualidade do ensino na graduação, e não é comum alunos de mestrado ou doutorado envolvendo-se com bacharelandos de iniciação científica para promover uma rede de pesquisa em todos os níveis de conhecimento contábil. Em adição, o entrevistado advogou ainda que a maioria dos docentes que lecionam tanto na graduação quanto nos programas de mestrado e doutorado tendem a priorizar as pesquisas com os pós-graduandos, para obtenção da pontuação necessária perante a Capes e negligenciarem as tarefas de ensino e extensão.

Em suma, a percepção dos respondentes quanto à questão da socialização acadêmica em sua forma pura e livre de vieses é que esse processo é muito importante para a formação de um cientista contábil, visto que treina o discente a atuar como pesquisador. Porém, todos concordaram que, no cenário da pesquisa contábil atual, a prática da socialização acadêmica não é realizada de forma isenta dos interesses publicacionistas, e a preocupação maior não é com o treinamento formal, político e ético no ambiente científico, mas com o número de artigos que o aluno pode produzir em seu tempo de vinculação com o programa de pós-graduação, não importando a qualidade sofrível que tais comunicações podem apresentar ou a incapacidade de tais publicações surpreenderem por representarem repetidas replicações de um mesmo estudo.

É relevante ressaltar que a maior parte dos programas de pós-graduação preocupa-se em treinar, de forma parcial e algumas vezes precária, os discentes nas qualidades formais e não tomam cuidado em habilitá-los para as qualidades políticas e éticas relacionadas à pesquisa. Nesse sentido, Demo (1995) assevera ser necessário reconhecer que somente a qualidade formal com domínio metodológico e teórico não basta para que um indivíduo se torne um cientista social, é preciso também que o agente se apresente como cidadão e ator político ao investigar problemas que envolvem a sociedade, sob pena de se tornar um “idiota especializado" (p. 25). Em adição, o autor afiança, que para a maioria dos estudiosos:

[...] a qualidade do cientista está em ser competente formalmente: domínio dos instrumentos metodológicos; capacidade no trato dos dados, bem como em sua coleta; versatilidade teórica, comprovada no conhecimento que tem da matéria, das discussões em voga na praça, dos clássicos; raciocínio lógico, matemático; rigor e disciplina diante do objeto, que deve dissecar, analisar, decompor; superação formal das fases na formação, segundo os ritos usuais da academia; e assim por diante (p. 23).

Nesses termos, Demo (1995) defende que a qualidade política não substitui nem é maior que a qualidade formal, contudo é essencial para a formação de um cientista social; e não se pode deixar de lado que a Contabilidade é uma ciência social aplicada. Assim sendo, o autor complementa que a qualidade política abrange "[...] todas as dimensões humanas que não se reduzem a expressões materiais, como cultura, educação, mundo simbólico, arte, ideologia, mas tem como conteúdo mais específico o fenômeno participativo [...]" (p. 25), ou seja, é o atributo que confere ao cientista a capacidade de se pronunciar criticamente, por vezes, até de forma contundente, frente aos problemas políticos e éticos que encontra em suas pesquisas, mesmo que tal pensamento seja contrário ao mainstream presente no campo. 
Desse modo, percebeu-se, pela fala dos respondentes, que o campo de pesquisa científica contábil, ainda de forma incipiente, repassa para os pós-graduandos as ideias da competência formal e deixa em segundo plano a qualidade política e ética da pesquisa e, por esse motivo, a socialização acadêmica no campo científico-contábil não é completa e deixa algumas lacunas nesse processo. Tal consideração pode ser confirmada por algumas características mencionadas pelos entrevistados, entre elas:

[1] a maior parte das disciplinas cursadas nos programas de mestrado e doutorado privilegiam o formato de aulas expositivas pelos docentes ou seminários pelos discentes, por meio dos quais não se fomentam o debate e as discussões acerca das temáticas tratadas, dificultando assim a avaliação crítica e a participação ativa dos alunos. Para os respondentes, o melhor formato de aula é aquele no qual são debatidos e criticados estudos científicos da área aliados a problemas reais da sociedade, pois só assim são gerados insights para futuras pesquisas que sejam originais, importantes e viáveis;

[2] as exigências de produção de artigos científicos para publicação em disciplinas também é uma realidade e isso faz com que se tenha um ambiente publicacionista e voltado para as qualidades formais apenas, visto que, nesse caso, o importante é apresentar uma comunicação lógica e bem sistematizada em termos de instrumental teórico e metodológico, sem importar muito se os resultados da investigação têm um caráter social e capacidade de surpreender e modificar o status quo da área. Alguns entrevistados mencionaram que conhecem docentes, nos PPGs da área contábil, que atrelam o conceito A ou B da disciplina à publicação de um artigo em periódico que possua avaliação positiva no programa Qualis da Capes;

[3] nas publicações científicas da área contábil, geralmente, há uma separação clara entre teoria e prática, o que não deveria acontecer. Esse fato pode ser comprovado mediante a leitura dos artigos que, com raras exceções, não possuem fundamentação teórica, mas somente conceitos utilizados na prática e replicados de estudos anteriores; ou em estudos teóricos que não possuem nenhuma conexão com a prática. Em ambos os casos, percebe-se o gap existente entre o que se escreve e o interesse do que está sendo escrito para a sociedade como um todo. Nesse âmbito, Demo (1995) defende que:

[...] para muitos cientistas sociais a prática aparece como espúria, como atividade menor, como incômoda; restringem-se à 'prática teórica', seja como fuga de compromissos que trazem riscos, seja para evitar ter de corrigir a teoria sob o impacto da prática, seja para escamotear práticas conservadoras sob a capa de teorias pretensamente avançadas, seja para angariar a imagem de imparcial, acima de qualquer suspeita, o que lhe abre o caminho da manipulação 'objetiva' (p. 34);

[4] para os respondentes, ainda existe, por parte de alguns docentes vinculados aos PPGs em Contabilidade, uma espécie de medo ou dificuldade em sair de sua zona de conforto e agir de forma crítica, por meio da competência política, contestando as estruturas do campo que fazem a estagnação científica ocorrer, escondendo-se atrás da chamada neutralidade científica. Nesse caso, esse tipo de atitude imparcial e conservadora é repassada aos discentes, e assim ocorre o fenômeno da reprodução social que se consolida e forma um habitus legitimado e difícil de ser modificado;

[5] no campo contábil, existe um processo de intersubjetividade bem presente, isto é, pesquisadores que possuem maior capital simbólico no campo determinam os rumos das investigações científicas. Nesse contexto, a Entrevistada 8 asseverou que "[...] a Contabilidade tem um foco, uma ênfase grande na abordagem positivista, então se o grupo entende que essa abordagem é o jeito de fazer pesquisa, fica difícil para quem não é, ou quem não realiza um estudo dentro dessa abordagem conseguir publicar na área [...]", ou seja, a socialização acadêmica em Contabilidade também sofre a influência do que os pesquisadores dominantes da área entendem como sendo a forma mais "correta" de obtenção da "verdade científica".

Logo, observou-se que as problemáticas evidenciadas no habitus dos agentes do campo científico-contábil também possuem sua gênese nos atributos de formação dos pesquisadores em Contabilidade que são ofertados pelos cursos de pós-graduação da área. Contudo, é importante destacar que o processo de socialização acadêmica não é a única variável que interfere na qualidade das publicações científicas contábeis. 


\section{Considerações Finais e Implicações do Estudo}

O objetivo da presente investigação foi levantar as influências da socialização acadêmica, promovida pelos programas de pós-graduação stricto sensu em Contabilidade, no desenvolvimento da produção científica do campo, no Brasil. Nesses termos, averiguou-se que os programas de pós-graduação stricto sensu também são pressionados pelos órgãos reguladores de pesquisas brasileiros, repassando aos docentes e discentes essa necessidade de publicação para continuar existindo.

Diante dessa problemática, os entrevistados defenderam que a maior parte dos PPGs utiliza como critério de avaliação nas disciplinas a publicação de um manuscrito ou artigo, no qual exista a participação do docente, ao menos na coautoria, visto que esse é um dos critérios avaliativos para que os PPGs continuem credenciados e recomendados pela Capes. Também foi evidenciado que o aluno é preparado para atender à qualidade formal nas publicações, deixando em segundo plano a qualidade política de criticar, debater e se opor, por meio da argumentação científica, às temáticas já consagradas como verdades quase inquestionáveis no campo contábil.

Assim sendo, a principal contribuição deste artigo é trazer à superfície elementos pouco debatidos na área acadêmica com relação ao processo de disseminação de publicações acadêmicas, que prioriza a contagem numérica desses estudos em periódicos e congressos de boa reputação da área, em detrimento da qualidade dessas publicações, as quais servem de base para a evolução e consolidação do campo de pesquisa científico contábil, utilizando como elemento primário desse processo a socialização acadêmica agenciada pelos PPGs stricto sensu em Contabilidade.

Entretanto, qualquer pesquisa também possui algumas restrições em seus resultados, para esta investigação, as limitações foram: [1] por ser uma pesquisa predominantemente qualitativa e em profundidade, as amostras de respondentes (nove) não permitem análises muito maiores e mais generalizadas sobre a temática tratada no artigo; e [2] entrevistas pressupõe uma certa subjetividade na interpretação por parte do pesquisador, e, também o entrevistado pode ocultar verdades, com o objetivo de permanecer em uma zona de conforto, evitando, assim, se pronunciar sobre causas polêmicas ou que exijam uma avaliação crítica. Por fim, sugere-se que sejam realizadas mais pesquisas sobre essa temática, para que se possa avançar no entendimento de outros fatores condicionantes do contexto social das pesquisas em Contabilidade no Brasil.

\section{Referências}

Alcadipani, R. (2011). Resistir ao produtivismo: uma ode à perturbação acadêmica. Caderno EBAPE.BR, 9(4), opinião 3, pp. 1174-1178. http://dx.doi.org/10.1590/S1679- 39512011000400015.

Andrade, J. X. (2011). Má conduta na pesquisa em Ciências Contábeis. Tese de Doutorado em Ciências Contábeis, Programa de Pós-Graduação em Ciências Contábeis, Faculdade de Economia, Administração e Contabilidade da Universidade de São Paulo. São Paulo, SP, Brasil.

Baggs, J. G. (2008). Issues and rules for authors concerning authorship versus acknowledgements, dual publication, self plagiarism and salami publishing [Editorial]. Research in Nursing \& Health, 31, pp. 295-297. doi: 10.1002/nur.20280.

Bardin, L. (2009). Análise de Conteúdo. $4^{\mathrm{a}}$ ed. Lisboa: Edições 70.

Berger, P. L., \& Luckmann, T. (2008). A construção social da realidade. 28ª ed. Petrópolis: Vozes.

Bertero, C. O., Caldas, M. P., \& Wood Jr., T. (1999). Produção científica em administração de empresas: provocações, insinuações e contribuições para um debate local. RAC - Revista de Administração Contemporânea, 3(1), pp. 147-178. http://dx.doi.org/10.1590/S1415-65551999000100009. 
Bianchi, A. (2014). Avaliação acadêmica: muito além do jardim. Blog Convergência. Recuperado em 19 março, 2014, de $<$ http://blogconvergencia.org/blogconvergencia/? $\mathrm{p}=1915>$.

Bourdieu, P. (2004). Os usos sociais da ciência: por uma sociologia clínica do campo científico. São Paulo: Editora Unesp.

Broome, M. E. (2004). Self-plagiarism: Oxymoron, fair use, or scientific misconduct? [Editorial]. Nursing Outlook, 52(6), pp. 273-274. http://dx.doi.org/10.1016/j.outlook. 2004.10.001

Camí, J. (1997). Impactolatría: diagnóstico y tratamiento. Medicina Clínica, 109(13), pp. 515-524.

CAPES (2004). Portaria no 068, de 03 de agosto de 2004. Brasília.

CAPES. (2016). Coordenação de Aperfeiçoamento de Pessoal de Nível Superior. Recuperado em 7 junho, 2016 de http://www.capes.gov.br/.

Castiel, L. D., \& Sanz-Valero, J. (2007). Entre fetichismo e sobrevivência: o artigo científico é uma mercadoria acadêmica? Caderno de Saúde Pública, 23(12), pp. 3041-3050. http://dx.doi.org/10.1590/ S0102-311X2007001200026.

Chow, C. W., \& Harrison, P. D. (1998). Factors contributing to success in research and publications: insights of 'influential' accounting authors. Journal of Accounting Education, 16, pp. 463-472. doi:10.1016/ S0748-5751(98)00030-X.

Chow, C. W., \& Harrison, P. D. (2002). Identifying meaningful and significant topics for research and publication: a sharing of experiences and insights by 'influential' accounting authors. Journal of Accounting Education, 20, pp. 183-203. doi:10.1016/S0748-5751(02)00008-8.

Cunha, J. V. A. (2007). Doutores de Ciências Contábeis da FEA/USP: Análise sob a Óptica da Teoria do Capital Humano. Tese de Doutorado em Ciências Contábeis, Programa de Pós-Graduação em Ciências Contábeis, Faculdade de Economia, Administração e Contabilidade da Universidade de São Paulo. São Paulo, SP, Brasil.

Costa, F. (2016). A presença do homo academicus na contabilidade: um olhar bourdieusiano sobre o contexto social do desenvolvimento da produção científica contábil brasileira. Tese de Doutorado em Ciências Contábeis, Programa de Pós-Graduação em Ciências Contábeis, Faculdade de Economia, Administração e Contabilidade da Universidade de São Paulo. São Paulo, SP, Brasil.

Demo, P. (1995). Metodologia Científica em Ciências Sociais. 3ª ed. São Paulo: Atlas.

Domingues, I. (2014). O sistema de comunicação da ciência e o taylorismo acadêmico: questionamentos e alternativas. Estudos Avançados, 28(81), pp. 225-250. http://dx.doi.org/10.1590/S010340142014000300014.

Duarte Jr., J. F. (2008). O que é realidade? São Paulo: Brasiliense.

Harzing, A-W. (2005). Australian Research Output in Economics \& Business: high volume, low impact? The Australian Journal of Management, 30(2), pp. 183-200.

Lei n. 5.540, de 28 de novembro de 1968 (1968). Fixa normas de organização e funcionamento do ensino superior e sua articulação com a escola média, e dá outras providências. Brasília, DF. Recuperado em 17 junho, 2016, de http://www.planalto.gov. br/ ccivil_03/leis/L5540.htm

Lei n. 9.394, de 20 de dezembro de 1996 (1996). Estabelece as diretrizes e bases da educação nacional. Brasília, DF. Recuperado em 17 junho, 2016, de http://www.planalto.gov.br/ ccivil_03/leis/L9394.htm

Lowe, N. K. (2003). Publication ethics: copyright and self-plagiarism [Editorial]. Journal of Obstetric, Gynecologic and Neonatal Nursing, 32(2), pp. 145-146. doi: 10.1111/j.1552-6909.2003.tb00137.x.

Martins, G. A. (2007). Avaliação das avaliações de textos científicos sobre contabilidade e controladoria. Revista de Educação e Pesquisa em Contabilidade, 1(1), pp. 1-13. http://dx.doi.org/10.17524/repec.v1i1.1. 
Martins, G. A., \& Theóphilo, C. R. (2009). Metodologia da Investigação Científica para Ciências Sociais Aplicadas. $2^{\mathrm{a}}$ ed. São Paulo: Atlas.

Martins, O. S., \& Lucena, W. G. L. (2014). Produtivismo acadêmico: as práticas dos docentes dos Programas de Pós-Graduação em Contabilidade. Advances in Scientific and Applied Accounting, 7(1), pp. 66-96. http://dx.doi.org/10.14392/asaa.v7i1.123.

McKneally, M. (2006). Put my name in that paper: Reflections on the ethics of authorship [Editorial]. The Journal of Thoracic and Cardiovascular Surgery, 131(3), pp. 517-519. http://dx.doi.org/10.1016/j. jtcvs.2005.09.060.

Moizer, P. (2009). Publishing in accounting journals: A fair game? Accounting, Organizations and Society, 34(2), pp. 285-304. doi:10.1016/j.aos.2008.08.003.

Peleias, I. R., Silva, G. P., Segreti, J. B., \& Chirotto, A. R. (2007). Evolução do ensino da contabilidade no Brasil: Uma análise histórica. Revista Contabilidade \& Finanças, Edição 30 anos de Doutorado, pp. 19-32. doi: 10.1590/S1519-70772007000300003.

Reinach, F. (27 de abril de 2013). Darwin e a prática da 'Salami Science'. O Estado de São Paulo. Recuperado em 5 fevereiro, $2014 \mathrm{de}<\mathrm{http}: / /$ www.estadao.com.br/noticias/impresso,darwin-e-a-pratica-da-salami-science, $1026037,0 . h t m>$.

Righetti, S. (22 de abril de 2013). Brasil cresce em produção científica, mas índice de qualidade cai. Folha de São Paulo. Recuperado em 5 fevereiro, 2014 de <http://www1.folha.uol.com.br/ciencia/ 2013/04/1266521-brasil-cresce-em-producao-cientifica-mas-indice-de-qualidade-cai.shtml>.

Samuelson, P. (Agosto de 1994). Self-plagiarism or fair use? Communications of the ACM, 37(8), pp. 21-25.

Schekman, R. (9 de dezembro de 2013). How journals like Nature, Cell and Science are damaging science. The Guardian. Recuperado em 10 março, 2014, de <http://www.theguardian.com/ commentisfree/2013/dec/09/how-journals-nature-science-cell-damage-science $>$.

Souza, T. A. S. (2007). O inato e o apreendido: A noção de habitus na sociologia de Pierre Bourdieu. Dissertação de Mestrado em Sociologia da Universidade de Brasília. Brasília,DF, Brasil.

Theóphilo, C. R. (2000). Uma Abordagem Epistemológica da Pesquisa em Contabilidade. Dissertação de Mestrado em Ciências Contábeis, Programa de Pós-Graduação em Ciências Contábeis, Faculdade de Economia, Administração e Contabilidade da Universidade de São Paulo. São Paulo, SP, Brasil.

Theóphilo, C. R. (2004). Pesquisa em Contabilidade no Brasil: Uma Análise Crítico-Epistemológica. Tese de Doutorado em Ciências Contábeis, Programa de Pós-Graduação em Ciências Contábeis, Faculdade de Economia, Administração e Contabilidade da Universidade de São Paulo. São Paulo, SP, Brasil.

Thomaz, P. G., \& Muramoto, G. (2012). Avaliação da qualidade da produção científica brasileira: Devemos criar uma política de cotas? [Carta ao Editor]. Revista do Colégio Brasileiro de Cirurgiões, 39(2), pp. 168-170. http://dx.doi.org/10.1590/S0100-69912012000200017.

Trigueiro, M. G. S. (2001). A formação de cientistas: necessidades e soluções. In M. Baumgarten [organizadora]. A era do conhecimento: Matrix ou Ágora? (pp. 61-70). Porto Alegre / Brasília: Editora da Universidade UFRGS / Editora UnB.

Wood Jr., T. (31 de janeiro de 2014). A favor da sociedade: As instituições de ensino e pesquisa deveriam orientar mais explicitamente suas ações e políticas, de modo a gerar benefícios tangíveis. Revista Carta Capital. Recuperado em 5 fevereiro, 2014, de < http://www.cartacapital.com.br/revista/784/a-favor-da-sociedade-1229.html>. 
Wood Jr., T. (24 de maio de 2016). Produtivismo e alienação. Revista Carta Capital. Recuperado em 17 junho, $2016 \mathrm{de}<\mathrm{http} / /$ www.cartacapital.com.br/revista/901/produtivismo-e-alienacao $>$. Acesso em: 17. jun. 2016.

Wreszinsky, W. F. (Outubro de 2012). O mito da excelência acadêmica e a curiosidade científica. Jornal da USP, pp. 12-13.

Yamamoto, O. H., Tourinho, E. Z., Bastos, A. V. B., \& Menandro, P. R. M. (2012). Produção científica e "produtivismo": há alguma luz no final do túnel? RBPG - Revista Brasileira de Pós-Graduação, 9(18), pp 727-750.

Zago, M. A. (2011). Perfil da produção científica brasileira. In Mesa de Discussão Tecnológica. São Paulo: FAPESP. Recuperado em 5 fevereiro, 2014, de <http://www.fapesp.br/eventos /2011/06/Marco_Antonio.pdf>. 